\title{
Methodological quality of clinical practice guidelines on probiotics in acute gastroenteritis in children using the appraisal of guidelines for research \& evaluation II instrument (AGREE II)
}

\begin{abstract}
Acute Gastroenteritis (AGE) is one of the diseases that most frequently affects paediatric population. Successful treatment in AGE has been mainly based on prevention and treatment of its complications; however every day, we find more publications on the use of adjuvants to decrease its duration. Some probiotics report benefits, particularly in terms of reducing duration of the episode or stool frequency. We look for clinical guidelines that recommend their use in AGE in children and we assessed their methodology quality by the Appraisal of Guidelines for Research \& Evaluation (AGREE II) instrument. All of the CPG consider that the administration of Lactobacillus rhamnosus GG and Saccharomyces boulardii should be considered in the management of children with AGE as an adjunct to rehydration therapy with different levels of evidence. Four CPG had one rating higher than $60 \%$ in 4 or more domains and one in only one domain. Only a CPG was greater than $60 \%$ in all domains. Four had an overall score greater than or equal to 5 and were 'recommended', and one with modifications, according to the instrument AGREE II. In conclusion: the selected GPC have good methodological quality, but are not specific to probiotics. Despite, they should be spread for better decision making.
\end{abstract}

Keywords: acute gastroenteritis, AGREE instrument, child, guidelines, probiotics
Volume 9 Issue 2 - 2018

\author{
Aldo Maruy Saito, ${ }^{1,2}$ Julio César Herrera \\ Rodríguez, ${ }^{1,2}$ Raúl Rojas Galarza ${ }^{3}$ \\ 'Hospital Cayetano Heredia, Perú \\ ¿Universidad Peruana Cayetano Heredia, Perú \\ 3Universidad Peruana de Ciencias Aplicadas - UPC, Perú
}

Correspondence: Aldo Maruy Saito, Universidad Peruana Cayetano Heredia, Lima, Perú, Email aldo.maruy@gmail.com

Received: December 22, 2017| Published: April 13, 2018

\section{Introduction}

Acute gastroenteritis (AGE) remains a major cause of morbidity and mortality in children around the world, accounting for 1.34 million deaths annually in children younger than 5 years, or roughly $15 \%$ of all child deaths. ${ }^{1}$ Successful treatment in AGE has been mainly based on prevention and treatment of its complications; however every day, we find more publications on the use of adjuvants to decrease its duration. Probiotics are live microorganisms that, when administered in adequate amounts, confer a health benefit on the host and have gained greater importance because some of them report benefits, particularly in terms of reducing duration of the episode or stool frequency. ${ }^{2}$

Clinical practice guidelines (CPGs) are systematically developed statements to assist practitioners in making decisions about appropriate health care in specific clinical circumstances. ${ }^{3}$ Their purpose is to make recommendations with a definite intent to influence what clinicians do. The benefits of guidelines are only as good as the quality of the guidelines themselves. The quality of guidelines can be extremely variable and some often fall short of basic standards. ${ }^{4,5}$

The Appraisal of Guidelines for REsearch \& Evaluation (AGREE) Instrument was developed to address the issue of variability in guideline quality. ${ }^{6}$ To that end, the AGREE instrument is a tool that assesses the methodological rigour and transparency in which a guideline is developed. The aim was to assess the methodological quality of clinical practice guidelines (CPG) on the use of probiotics in infant diarrhoea.

\section{Materials and methods}

The search was conducted in December 2016, of CPG based on the evidence, the last 10 years and unrestricted language, PubMed, ScienceDirect, and Lilacs. In PubMed, the search terms were: probiotics AND infants; limit: 'guideline'. In ScienceDirect: Probiotics AND infants; limit: Medicine and Dentistry and LILACS: 'probiotics' AND 'infants' and 'probióticos' AND 'guía'. The CPG selected were evaluated with the instrument AGREE II by two evaluators who were independent one from the other and by a third evaluator, when there were discrepancies. The concordance of the evaluations was measured with the index of kappa.

\section{Results}

Ten documents were recovered in PubMed, and selected only 03 that fulfilled the criteria about probiotics. No documents were recovered in the other two searchers. The other two were located in a direct way. The 5 CPG were: 1 . Diarrhea and vomiting caused by gastroenteritis - NICE (2009); ${ }^{7}$ 2. CPG on the diagnosis and treatment of the AID in Pediatrics - Peru (2009); ${ }^{8,9}$ 3. ESPGHAN-ESPID evidence-based guidelines for the management of AGE in children in Europe. Update (2014); ;0,11 4. Clinical practice guideline ILA on the management of GEA in children under 5 years $(2014)^{12}$ and 5 . Use of probiotics for management of AGE. A position paper by the ESPGHAN Working Group for Probiotics and Prebiotics (2014). ${ }^{13}$ All of the CPG consider that the administration of Lactobacillus rhamnosus GG and Saccharomyces boulardii should be considered in the management of children with AGE as an adjunct to rehydration 
therapy with different levels of evidence. The concordance between evaluators was $>0.9$ and $<1.0$ for all guidelines.

Four CPG had one rating higher than $60 \%$ in 4 or more domains and one in only one domain. Only a CPG was greater than $60 \%$ in all domains. Four had an overall score greater than or equal to 5 and were 'recommended', and one with modifications, according to the instrument AGREE II.

\section{Discussion}

As a result of our study, using the AGREE II instrument, 4 CPGs of 'Recommendable' quality were identified for the AGE, which recommended the use of probiotics as coadjuvant therapy. A publication, called CPG, was globally rated as 'Recommendable with modifications' because it is a consensus and the AGREE II instrument, only values CPGs. Our study is one of the first and few studies that evaluates the CPG on AGE with the AGREE II instrument and that allows the elaboration of a hierarchical table of recommendations on the use of probiotics in AGE, different from the study that uses the

\section{AGREE I instrument (Table 1). ${ }^{14}$}

The use of probiotics as adjuvant therapy for AGE in pediatrics has solid arguments. ${ }^{2,15}$ Therefore, the need to evaluate the quality of the CPGs that recommend them is important because, as shown in other studies, both nationally and internationally, the quality of CPG preparation is variable. ${ }^{16,17}$ The study showed that the overall quality of the CPGs evaluated is 'high' ('Recommendable'), but that despite this, the assessment of the Applicability domain is low, as was found in another publication, ${ }^{18}$ leading to think that the probability of implementation is controversial. This could explain, in part, the poor adherence shown by physicians in following CPG recommendations. ${ }^{19-21}$ In the domains of Scope and objectives and Presentation, all the guides obtain their best assessment, which reflects that the developers are standardizing to whom is directed and how to present the CPG, however, due to the variability in the process of development and scientific content there is still no confidence in following the $\mathrm{CPG}$, as has been analyzed in some noncommunicable diseases, for example. ${ }^{22}$

Table I Recommendations on the use of probiotics in AGE

\begin{tabular}{llllll}
\hline Domain & NICE & Gonzales et al. & $\begin{array}{l}\text { Guarino et } \\
\text { al. }\end{array}$ & $\begin{array}{l}\text { Polanco et } \\
\text { al. }{ }^{12}\end{array}$ & $\begin{array}{l}\text { Szajewska et } \\
\text { al. }^{13}\end{array}$ \\
\hline $\begin{array}{l}\text { I. Scope and Purpose } \\
\text { 2. Stakeholder Involvement }\end{array}$ & $97.22 \%$ & $100.00 \%$ & $83.33 \%$ & $88.89 \%$ & $19.44 \%$ \\
$\begin{array}{l}\text { 3. Rigour of Development } \\
\text { 4. Clarity of Presentation }\end{array}$ & $78.89 \%$ & $80.56 \%$ & $77.78 \%$ & $69.44 \%$ & $30.56 \%$ \\
$\begin{array}{l}\text { 5. Applicability } \\
\text { 6. Editorial Independence }\end{array}$ & $97.22 \%$ & $100.00 \%$ & $80.56 \%$ & $69.44 \%$ & $61.11 \%$ \\
Rate Overall Quality & $68.75 \%$ & $58.33 \%$ & $54.17 \%$ & $41.67 \%$ & $27.08 \%$ \\
Recommendation & $70.83 \%$ & $75.00 \%$ & 62.5 & $62.50 \%$ & $58.33 \%$ \\
\hline
\end{tabular}

Globally, there is an attempt to reduce inequality in the provision of health services; this will not be possible if a quality health care is not delivered and above all measurable, in order to improve it continuously, as an analysis of the improvement model in Europe has shown. ${ }^{23}$ Thus, the AGREE II instrument is used by health institutions and health policymakers to discriminate on recommended or not recommended guidelines for infectious ${ }^{24}$ and non-infectious diseases in pediatrics. ${ }^{25}$ The evaluation methodology of the CPGs with the AGREE II instrument is known and has been the subject of publications to explain the influence of the evaluation and the importance of the components of the instrument, to try to be as objective as possible. ${ }^{26}$

It is important to notice that the position paper by the ESPGHAN ${ }^{13}$ has a search methodology and elaboration of recommendations of the most updated, disseminated and recognized which is the GRADE methodology, ${ }^{27}$ but it is not a GPC. For our study, when evaluated by the AGREE II instrument, its assessment is 'recommended with modifications' without diminishing its quality in the content or in the elaboration. Therefore, its use as a 'source' in decision-making, although it is not known if it has been evaluated, could be one of the most consulted.

In recent years, medical malpractice lawsuits have turned traditional medicine into a 'defensive' type medicine, ${ }^{28,29}$ increasing the costs of medical care and generating distrust in the system. The possibility of a medical malpractice judgement will always be present each time an attention is made. The practice of evidence-based medicine is not an infallible practice and the legal influence of CPGs has been evaluated, especially to help the courts decide whether a negligence claim is sustainable or not. ${ }^{30}$ For this reason, quality CPGs that help in decision-making, with scientific and trustworthy information, will not only benefit the patient (since health care, with high probability, will be of quality), but will help the health system to be safer and more useful to the patient.

The results of our study can be extrapolated to other medicine topics, both in communicable diseases, ${ }^{31}$ as in non-communicable diseases. ${ }^{32,33}$ The main limitation is the number of documents that are 'cataloged' as CPG and they are not and this can increase the documents quantity to be selected and also, that the same documents have a 'Not recommended' assessment by the AGREE II instrument. The concordance in the evaluation of the documents evaluated, measured by the Kappa index, was between 0.9 and 1.0 (almost perfect correlation). ${ }^{34,35}$ But it is important to notice that the methodologists who conducted the evaluation and their mastery on the AGREE II instrument are a scarce resource for similar work, because the evaluation methodology, although it is widespread, is not necessarily of interest to health policymakers at national level and for that reason, 
the promotion of these competences for later works will depend on the professionals who dominate the assessment methodology.

The value of CPGs that have 'Recommendable' quality is difficult to implement by physicians and this makes it controversial. ${ }^{36,37}$ Thus, proposals to improve Applicability, which include both assistance measures (attention feedback, analysis of implementation barriers) and administrative measures (economic opinion in health, audits), acquire great importance. ${ }^{18}$

With the selection and evaluation of CPG carried out, it is possible to elaborate a hierarchical table with recommendations, from the GPC of 'Recommendable' quality; this would benefit the pediatric population and allow the optimization and rationalization of the use of resources in one of the main pathologies of pediatric, such as the AGE. The future analysis should focus on identifying the 'Recommended' CPGs and working with them on the Applicability, to improve their adherence and thus the offer of health services provided to the patient. Finally, we believe that the results of this study will be of great interest to health policymakers and health institutions.

\section{Conclusion}

The selected GPC have good methodological quality, but are not specific to probiotics. Despite, they should be spread for better decision making.

\section{Acknowledgements}

Nilton Yhuri Carreazo-Pariasca and Miguel Chipana-Osiro .

Biocodex who sponsored the open access editorial cost of this publication

\section{Conflict of interest}

The author declares no conflict of interest.

\section{References}

1. Black RE, Cousens S, Johnson HL, et al. Global, regional, and national causes of child mortality in 2008: a systematic analysis. Lancet. 2010;375(9730):1969-87.

2. Cruchet S, Furnes R, Maruy A, et al. The use of probiotics in pediatric gastroenterology: a review of the literature and recommendations by Latin-American experts. Paediatr Drugs. 2015;17(3):199-216.

3. Institute of Medicine. Guidelines for Clinical Practice: From Development to Use. Washington, DC: National Academy Press; 1992.

4. Bazzano AN, Green E, Madison A, et al. Assessment of the quality and content of national and international guidelines on hypertensive disorders of pregnancy using the AGREE II instrument. BMJ Open. 2016;6:e009189.

5. Dersch R, Toews I, Sommer H, et al. Methodological quality of guidelines for management of Lyme neuroborreliosis. BMC Neurol. $2015 ; 15: 242$.

6. http://www.agreetrust.org

7. National Collaborating Centre for Women's and Children's Health (UK). Diarrhoea and vomiting caused by gastroenteritis: diagnosis, assessment and management in children younger than 5 years. NICE Clinical Guidelines, No. 84. London: RCOG Press; 2009.

8. Gonzales C, Bada C, Rojas R, et al. Guía de Práctica Clínica sobre el Diagnóstico y Tratamiento de la Diarrea Aguda Infecciosa en Pediatría Perú - 2011. Rev Gastroenterol Perú. 2011;31(3):258-277.

9. Gonzales $\mathrm{C}$, Bada C, Rojas R, et al. Guía de Práctica Clínica sobre el Diagnóstico y Tratamiento de la Diarrea Aguda Infecciosa en Pediatría Perú - 2011. Rev Gastroenterol Perú. 2012;32(1):100-104.

10. Guarino A, Albano F, Ashkenazi S, et al. ESPGHAN/ESPID evidencebased guidelines for the management of acute gastroenteritis in children in Europe. JPGN. 2008;46 Suppl 2:S81-122.

11. Guarino A, Ashkenazi S, Gendrel D, et al. European Society for Pediatric Gastroenterology, Hepatology, and Nutrition/European Society for Pediatric Infectious Diseases evidence-based guidelines for the management of acute gastroenteritis in children in Europe: update 2014. JPGN. 2014;59(1):132-52.

12. Polanco Allué I, Salazar-Lindo E, Gutiérrez-Castrellón P, et al. IberoLatinoamericano sobre el Manejo de la Diarrea Aguda (GILA). [Ibero-Latin American clinical practice guide on the management of acute gastroenteritis in children under 5 years: diagnostic and health care criteria]. An Pediatr (Barc). 2014;80 Suppl 1:5-8.

13. Szajewska H, Guarino A, Hojsak I, et al. Use of probiotics for management of acute gastroenteritis: a position paper by the ESPGHAN Working Group for Probiotics and Prebiotics. JPGN. 2014;58(4):531-9.

14. Lo Vecchio A, Giannattasio A, Duggan C, et al. Evaluation of the quality of guidelines for acute gastroenteritis in children with the AGREE instrument. J Pediatr Gastroenterol Nutr. 2011;52(2):1839.

15. Hojsak I. Probiotics in Children: What Is the Evidence? Pediatr Gastroenterol Hepatol Nutr. 2017;20(3):139-146.

16. Canelo-Aybar C, Balbin G, Perez-Gomez A, et al. Guías de práctica clínica en el Perú: evaluación de su calidad usando el instrumento AGREE II. Rev Peru Med Exp Salud Publica. 2016;33(4):732-8.

17. Chen YL, Yao L, Xiao XJ, et al. Quality assessment of clinical guidelines in China: 1993 - 2010. Chin Med J (Engl). 2012;125(20):3660-4.

18. Sabharwal S, Patel NK, Gauher S, et al. High methodologic quality but poor applicability: assessment of the AAOS guidelines using the AGREE II instrument. Clin Orthop Relat Res. 2014;472(6):1982-8.

19. Ryan MA. Adherence to Clinical Practice Guidelines. OtolaryngolHead Neck Surgery. 2017;157(4):548-550.

20. Khalil V, Danninger M, Wang W, et al. An audit of adherence to heart failure guidelines in an Australian hospital: A pharmacist perspective. J Eval Clin Pract. 2017;23(6):1195-1202.

21. Chapman SA, St Hill CA, Little MM, et al. Adherence to treatment guidelines: the association between stroke risk stratified comparing CHADS2 and CHA2DS2-VASc score levels and warfarin prescription for adult patients with atrial fibrillation. BMC Health Services Research. 2017;17(1):127.

22. Abdelsattar ZM, Reames BN, Regenbogen SE, et al. Critical Evaluation of the Scientific Content in Clinical Practice Guidelines. Cancer. 2015;121(5):783-9.

23. Bert F, Scaioli G, Gualano MR, et al. How can we bring public health in all policies? Strategies for healthy societies. J Public Health Res. 2015;4(1):393.

24. Wilby KJ, Black EK, MacLeod C, et al. Critical appraisal of clinical practice guidelines in pediatric infectious diseases. Int J Clin Pharm. 2015;37(5):799-807. 
25. Zeraatkar D, Nahari A, Wang PW, et al. Appraisal of clinical practice guidelines for management of paediatric type 2 diabetes mellitus using the AGREE II instrument: a systematic review protocol. Syst Rev. 2016;5(1):111.

26. Hoffmann-Eßer W, Siering U, Neugebauer EAM, et al. Guideline appraisal with AGREE II: Systematic review of the current evidence on how users handle the 2 overall assessments. PLOS ONE. 2017;12(3):e0174831.

27. Guyatt GH, Oxman AD, Vist GE, et al. GRADE: an emerging consensus on rating quality of evidence and strength of recommendations. BMJ. 2008;336(7650):924-6.

28. Hermer LD, Brody H. Defensive Medicine, Cost Containment, and Reform. J Gen Intern Med. 2010;25(5):470-473.

29. He AJ. The doctor-patient relationship, defensive medicine and overprescription in Chinese public hospitals: evidence from a crosssectional survey in Shenzhen city. Soc Sci Med. 2014;123:64-71.

30. Hurwitz B. How does evidence based guidance influence determinations of medical negligence? BMJ. 2004;329:1024-8.

31. Wilby KJ, Black EK, MacLeod C, et al. Critical appraisal of clinical practice guidelines in pediatric infectious diseases. Int J Clin Pharm. 2015;37(5):799-807.
32. He Z, Tian H, Song A, et al. Quality Appraisal of Clinical Practice Guidelines on Pancreatic Cancer. A PRISMA-Compliant Article. Medicine. 2015;94(12):e635.

33. Lucendo AJ, Molina-Infante J, Arias Á, et al. Guidelines on eosinophilic esophagitis: evidence-based statements and recommendations for diagnosis and management in children and adults. United European Gastroenterol J. 2017;5(3):335-358.

34. Landis JR, Koch GG. The Measurement of Observer Agreement for Categorical Data. Biometrics. 1977;33(1):159-174.

35. Cerda J, Villarroel L. Evaluación de la concordancia inter-observador en investigación pediátrica: Coeficiente de Kappa. Rev Chil Pediatr. 2008;79(1):54-58.

36. Pantoja T, Soto M. Clinical practice guidelines development and implementation: an introduction. Rev Med Chil. 2014;142(1):98-104.

37. Muche-Borowski C, Nothacker M, Kopp I. Implementation of clinical practice guidelines: how can we close the evidence-practice gap? Bundesgesundheitsblatt Gesundheitsforschung Gesundheitsschutz. 2015;58(1):32-7. 